\title{
VISUALIZATION OF FLOW SEPARATION AND CONTROL BY VORTEX GENERATORS ON AN SINGLE FLAP IN LANDING CONFIGURATION
}

\begin{abstract}
Natálie Součková, Jana Kuklová, Lukáš Popelka, Milan Matějka`
Abstract: This paper focuses on a suppression of the flow separation, which occurs on a deflected flap, by means of vortex generators (VG's). An airfoil NACA 63A421 with a simple flap and vane-type vortex generators were used. The investigation was carried out by using experimental and numerical methods. The data from the numerical simulation of the flapped airfoil without VG's control were used for the vortex generator design. Two sizes, two different shapes and various spacing of the vortex generators were tested. The flow past the airfoil was visualized through three methods, namely tuft filaments technique, oil and thermo camera visualization. The experiments were performed in closed circuit wind tunnels with closed and open test sections. The lift curves for both cases without and with vortex generators were acquired for a lift coefficient improvement determination. The improvement was achieved for several cases by means all of the applied methods.
\end{abstract}

\section{INTRODUCTION}

The flow visualization is an important part of experimental research projects providing valuable information about the flow behaviour. There are plenty of different well known visualization techniques verified by many years of use which are suitable for different group of similar cases [1]. However, it may happen that the chosen method for a particular case, under certain conditions, turns out to be inapplicable and then it is necessary to find more suitable well-proven method or to try some newer technique, as it appears in this work. Therefore the choice of visualization methods is always the crucial question of experimental research.

The other pivotal part of this paper is the vortex generators boundary layer separation control. The principle of vortex generator (VG) flow control is based on generation of vortical structures, which transfer the high momentum fluid towards the surface. The flow with higher momentum can resist greater unfavorable pressure gradients. This results in reduction or suppression of flow separation and related reduction of drag or noise, aerodynamic characteristic improvement, heat transfer enhancement, etc... [2].

\footnotetext{
•Academy of Sciences, Institute of Thermomechanics, Dolejškova 1402/5, 18200 Praha 8, Czech Republic,natalies@it.cas.cz,popelka@it.cas.cz

Czech Technical University in Prague, Faculty of Transportation Sciences, Department of Applied Mathematics, $\mathrm{Na}$ Florenci 25, 11000 Praha 1, Czech Republic, kuklojan@fd.cvut.cz Czech Technical University in Prague, Faculty of Mechanical Engineering, Department of Fluid Dynamics and Power Engineering, Milan.Matejka@fs.cvut.cz
}

This is an Open Access article distributed under the terms of the Creative Commons Attribution License 2.0, which permits unrestricted use, distribution, and reproduction in any medium, provided the original work is properly cited. 
The vortex generators (VGs) exist in different shapes and sizes. The VG position depends on flow parameters and flow separation location. This dependency limits the use of VGs for applications with relatively fixed location of flow separation. Because a pair or pairs of vortex generators are used rather than a single one, the other important parameters namely relative vortex generator placement, which influences the type of originating vortices, co-rotating or counter-rotating and spacing between particular VGs pairs have to be taken into account. Two main types of vortex generators are distinguished according to the ratio of VG height $\mathrm{h}$ and boundary layer height $\delta$ as a conventional VG $(h / \delta>0.5)$ and low-profile VG $(0.1<\mathrm{h} / \delta<0.5)$. Due to the conventional VGs drag penalties, the low-profile vortex generators are a subject of interest nowadays.

A lot of experimental research on vortex generator flow control has been performed. Thorough review of low-profile VGs investigation is focused on basic research, as well as airfoil wing and non-airfoil investigations [2]. It is obvious that there is an absence of comprehensive research of vortex generators relating all VG design parameters with behaviour of generated vortices and flow conditions. Moreover, not many numerical simulations have been performed in the area of airfoil section applications. One of these few studies is concerned with passive and active flow separation control. Direct numerical simulation (DNS) is used and the vortex generator is modeled by immersed-boundary method [3]. Unfortunately, there is a lack of solutions realized by commercial codes and those, which are solved this way, focus on heat transfer in a channel mainly.

This work is focused on the low-profile vortex generator control of flow separation on a deflected simple flap of an airfoil NACA 63A421 as the part of project oriented on VGs influence on flow conditions. In addition the three visualization methods are tested as a result of the need to clarify the confusing outcomes of using one of them.

The investigation was carried out using experimental and numerical methods. In the first step non-control case was solved by means of numerical simulation to determine the location of flow separation and airfoil boundary layer thickness. Information obtained from the numerical calculations was utilized for vortex generator design according to the best result of earlier measurements, who dealt with vortex generator flow control on a bump [4] and to the data for rectangular vane VG used also on bump [2]. VGs were then applied to the flapped airfoil and their influence on flow was investigated.

\section{EXPERIMENTS}

The efficiency of the vortex generators to remove or at least reduce the presence of the flow separation on a simple deflected flap and the VGs influence on flow over the flap were made out via tuft filaments, infrared thermography and oil visualization. Their contribution to the lift was

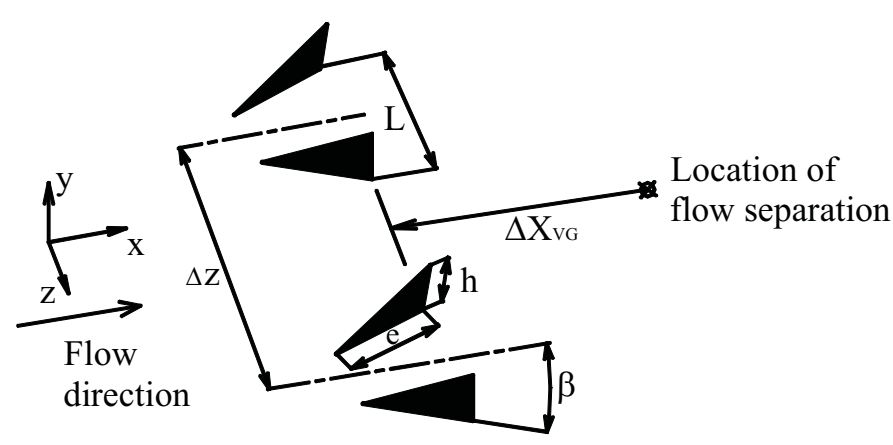

Figure 1 Triangular VGs and its relative position

determined through lift slope measurements. 


\begin{tabular}{ccccccccc}
\hline \hline & & $\mathrm{VGs}$ & $\mathrm{h} / \delta$ & $\Delta \mathrm{X}_{\mathrm{VG}} / \mathrm{h}$ & $\mathrm{e} / \mathrm{h}$ & $\mathrm{L} / \mathrm{h}$ & $\Delta \mathrm{z} / \mathrm{h}$ & $\beta$, deg. \\
\hline Godard & $\mathrm{CtR}$ & $\begin{array}{c}\text { Triangular } \\
\text { vanes }\end{array}$ & 0.37 & 57 & 2 & 2.5 & 6 & 18 \\
Lin & $\mathrm{CtR}$ & $\begin{array}{c}\text { Rectangular } \\
\text { vanes }\end{array}$ & 0.2 & 10 & 4 & - & 9 & 25 \\
\hline \hline
\end{tabular}

Table 1 Vortex generators design parameters

\subsection{Wind Tunnel, Model, Vortex Generators}

Both pressure distribution measurement and tuft filament visualization were carried out in the wind tunnel of the Department of Fluid Dynamics Laboratory of IT, AS CR. The closed circuit wind tunnel has a closed test section with dimensions of $865 \mathrm{~mm} \times 485 \mathrm{~mm} \times 900 \mathrm{~mm}$. The angle of attack changes are enabled by electrically driven circular endplates [5]. The infrared thermography and oil visualization was performed in the wind tunnel of the Division of Fluid Dynamics Laboratory of FME, CTU in Prague. The closed circuit wind tunnel has an open test section with cross-section dimensions of $750 \mathrm{~mm} \times 550 \mathrm{~mm}$ and the turbulence intensity is $3.5 \%$ at a free stream velocity of $16 \mathrm{~m} / \mathrm{s}$.

The model of NACA 63A421 airfoil with a simple flap was used. The model with chord length $250 \mathrm{~mm}$ and span $485 \mathrm{~mm}$ was fixed between two annular endplates made of transparent plexiglass. The flap chord ratio was $30 \%$. The model configurations were without flap deflection and with flap deflection of $20 \mathrm{deg}$.

Triangular and rectangular vane vortex generators were made of plastic sheet. The VGs heights were chosen as h1 $=1.5 \mathrm{~mm}$ (small VG) and h2 $=3 \mathrm{~mm}$ (large VG) for both types of VGs. The other dimensions were defined through the parameters in Table 1 . The whole process of vortex generators design is described in more detail in [6]. Then the VGs were stuck to the model surface in two specific locations in such a relative position of vortex generators within one pair so that they produce counter-rotating (CtR) vortices, as shown on Fig. 1. The locations of VGs pairs in non-dimensional form, defined as a ratio of the $x$-coordinate and chord length $(x / c)$, were $x_{1}=0.5632$ and $x_{2}=0.65$ downstream of leading edge. The distance of VGs from flow separation position is not mentioned on purpose, because it changes with angle of attack variations, see Table 2 . During measurement the spacing between VGs pairs was changed so that it either corresponded with parameters in Table. $1\left(\Delta z_{1}\right)$ or the spacing was in a half size $\left(\Delta z_{2}\right)$.

\begin{tabular}{ccc}
\hline \hline & \multicolumn{2}{c}{$\gamma$, deg. } \\
\cline { 2 - 3 }$\alpha$, deg. & 0 & 20 \\
\hline-5 & 0.9653 & 0.7429 \\
0 & 0.9195 & 0.7476 \\
5 & 0.7910 & 0.7385 \\
10 & 0.6036 & 0.5569 \\
15 & 0.4323 & 0.4330 \\
\hline \hline
\end{tabular}

Table 2 Non-dimensional flow separation locations
Although in introduction section was mentioned lowprofile VGs control, there are some cases, where the boundary layer height is so small that at the same height of vortex generators, they are not low-profile anymore. The reason is in changing of boundary layer height with angle of attack variation. Therefore the non low-profile VG cases are indicated.

All measurements were carried out at Reynolds number 200,000 and the range of angles of attack differed based on used measurement technique. 


\subsection{TUFT FILAMENTS VISUALIZATION}

Firstly the flow passing the model without vortex generators was visualized to achieve numerical results confirmation, namely absence of separation bubble somewhere.

The model was covered by tufts. The distance between tufts in each row depends on tuft length and was set so that they could not get caught mutually. Afterwards the tufts were kept only on the flap and visualization of controlled case was performed, see Fig. 2. Flow conditions stood with Table 3. The angles of attack were set in a range from -5 deg. to $15 \mathrm{deg}$.

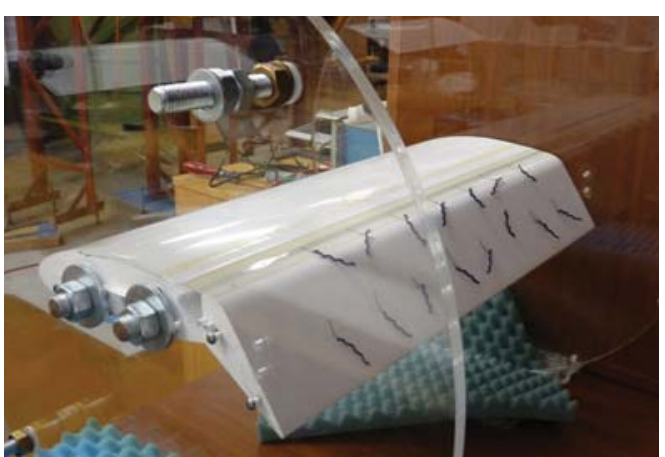

Figure 2 Tuft filaments placement on deflected flap

\subsection{Oil Visualization}

Owing to the unexpected results from Tuft filament measurement, which are described in Results and Discussion section in more detail, the oil visualization purely for zero angle of attack followed. Initially the

\begin{tabular}{ccc}
\hline \hline $\mathrm{v}_{\infty}, \mathrm{m} / \mathrm{s}$ & $\mathrm{Tu}, \%$ & $\mathrm{Re}$ \\
\hline 12 & 0.25 & 200,000 \\
\hline \hline
\end{tabular}

Table 3 Flow conditions measurement of the same non-controlled case was carried out and according to the gained results, where the separation bubble was observed, the zig-zag tape was fixed to upper surface of the model at non-dimensional downstream position of leading edge $x / c=0.23$. The fully turbulent flow over almost whole model was achieved, which led to separation bubble suppression. Then the measurement non-controlled as well as controlled cased both with the tape were performed. Since the measurement was not performed in the same wind tunnel as the previous one, the different turbulence intensity of free stream flow has to be pointed out.

\subsection{INFRARED THERMOGRAPHY VISUALIZATION}

The disadvantage of the oil visualization is considerable pollution of the circuit wind tunnel and its test section, which might be undesirable in term of further use of the wind tunnel. Thus the need to find other visualization method without such influence on the wind tunnel space and the airflow appeared. Infrared thermography visualization proves to be the most suitable and relatively easy to use, thus feasible technique with respect to known visualization methods.

Although this method was used for the first time more than 20 years ago, there is still lack of available information about experiments concerned infrared thermography investigation of boundary layer. Thus verification measurements were performed at first. The experiment was carried out in the same wind tunnel and at the same conditions as oil visualization for the same airfoil without deflected flap as well as without vortex generators and zig-zag tape, then results from both measurements were compared and very good agreement was achieved. The detailed description of whole measurement, process of evaluation and results is in [7].

After the measurement with vortex generators and zig-zag tape at flap deflection of 20 deg. was performed. The main difference against verification measurement was in flap deflection and with accompanying emissivity coefficient determination, which depends on the direction of radiation. It means that the emissivity coefficient value should be 
different for a main part of the airfoil and for the flap area. Nevertheless absolute values of temperature of particular cases were not our subject of interest but only the variations among them so the constant emissivity coefficient for the whole model was consider. The thermo camera ThermaCAM P65 of Faculty of Transportation Sciences was used. This camera has an accuracy \pm 2 Celsius deg., temperature sensitivity 0.08 Celsius deg. and three temperature ranges: $-10-+55$ Celsius deg., $-40-+120$ Celsius deg. and $0-+500$ Celsius deg. [7]. The model situated in the test section was heated before every measurement to obtain sufficient temperature difference between airflow and model surface. The whole open test section was covered with a black sheet, with an access for the camera lens.

\subsection{LIFT Slope MEASUREMENT}

The lift slope was determined from pressure distribution measurement. The model with the zig-zag tape was only used and both cases with and without VGs were measured likewise. The pressure orifices on side walls of the closed test section were employed to obtain the pressure distribution. Flow conditions were consistent with Tuft filaments visualization. The final lift slopes for angles of attack range from $-2.5 \mathrm{deg}$. to $22.5 \mathrm{deg}$. include all necessary corrections.

\section{Results and Discussion}

The results from Tuft filaments visualization show that the flow separation suppression on deflected flap was doubtless achieved only in case of large rectangular VGs $\left(x_{1}, \Delta z_{2}\right)$ at zero angle of attack, see

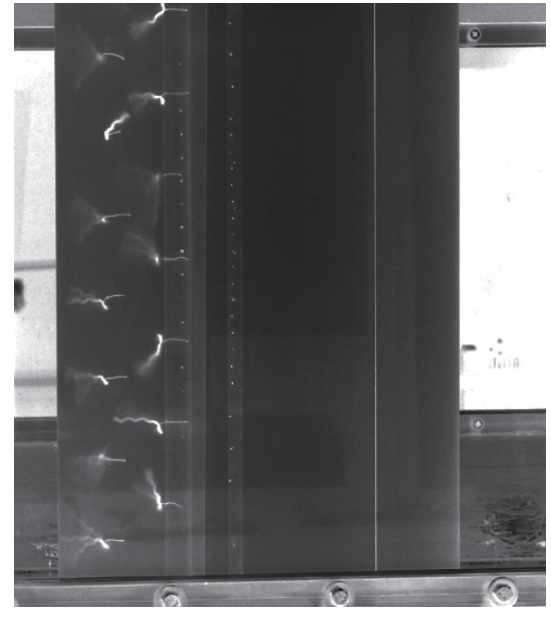

Figure 3a no VGs, $\gamma=20$ deg., $\alpha=0$ deg.

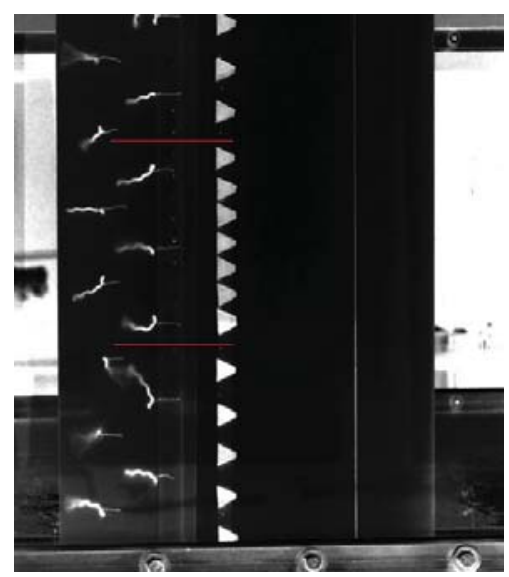

Figure 3b rectangular VGs $\left(h 2, x_{1}, \Delta z_{2}\right), \gamma=20$ deg., $\alpha=0$ deg. (the free stream flow direction is from right to left)

Fig 3a, 3b. The flow separation on the airfoil without flap deflection does not appear at any angle of attack, except at one corresponding to $15 \mathrm{deg} .$, where the separation starts approximately in the middle of the chord, thus upstream of the VGs. Notwithstanding the improvement was reached with large triangular VGs $\left(x_{1}, \Delta z_{2}\right)$, see Fig. $4 a, 4 b$. Both cases correspond with conventional type of vortex generators. Those findings seemed to be a little bit odd, hence the oil visualization and consequently infrared thermography visualization were carried out.

So firstly the oil visualization for plain model with and without flap deflection was performed. The separation bubble was clearly occurred there. Then the zig-zag tape was used to avoid this situation. The subsequent oil visualization confirmed the separation bubble elimination, see Fig. 5a, 5b. Thus the tuft filaments method seems to be inconvenient for purpose to which was used, because used tufts either affected the flow in the way that the transition of boundary layer came on or the present separation bubble was so small that tufts could not display it. So the results for controlled case from 
tuft filaments visualization likely did not display distinctly how efficient the VGs are in

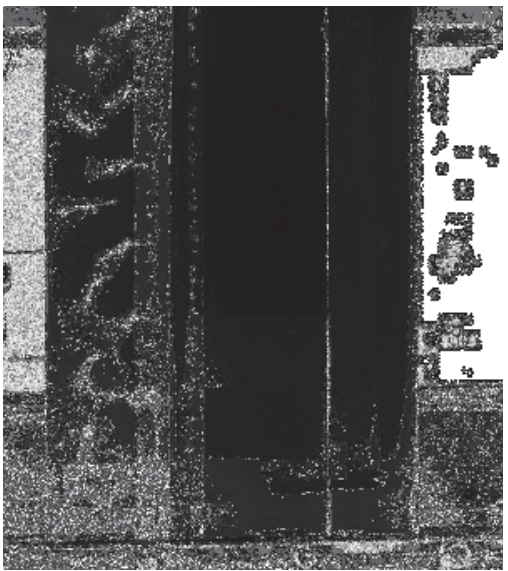

Figure 4a no VGs, $\gamma=0$ deg., $\alpha=15$ deg.

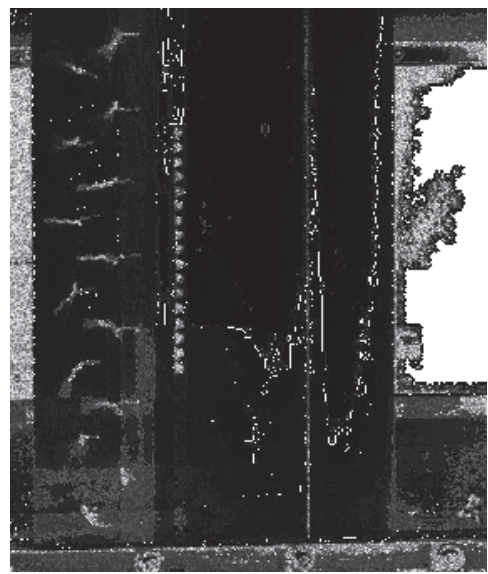

Figure 4b triangular VGs (h2, $\left.x_{1}, \Delta z_{2}\right) \gamma=0$ deg., $\alpha=15$ deg. (the free stream flow direction is from right to left)

term of suppression of flow separation on deflected flap, because in some cases the VGs were placed in the separation bubble and it could have influence on their efficiency, especially for the low-profile ones.

In additional some of these measurements were used to verify the infrared thermography visualization method, but the results are not discussed here in more detail.

Other measurements were focused on controlled cases. It turned out that the rectangular VGs had some effect in almost all cases. For small (low-profile) ones there was the more significant influence at the position closer to the flow separation location (Fig. 6a, 6b), where downstream displacement of separation location was achieved. The VGs effectiveness was better for larger spacing. The large rectangular VGs (conventional) had considerable effect in all cases. There was acquired separation shifting even more downstream than for the small ones, but the influence of the position from separation is not obvious (Fig. 7a, 7b). The triangular VGs had not practically any effect on separated flow, except the case of large VGs $\left(x_{2}, \Delta z_{1}\right)$, where only really slight effect was achieved, see Fig. 8.

Due to little experience with Infrared thermography visualization, from the results evaluation of using this method was expected to assess the possibility of employing the technique for such sort of experiments and even to gain better insight into vortex generators function in relation to flow separation suppression on

deflected flap. The graphs of evaluated non-dimensional temperature against nondimensional chord position confirm better the effectiveness of conventional rectangular VGs compared to low-profile ones, see Fig. 9. On the other hand, although no or only slight improvement was observed from oil visualization for low-profile and conventional triangular VGs, respectively, the slight improvement and quite obvious uplift was observed by this method, see Fig. 10. The comparison of results for conventional rectangular VGs

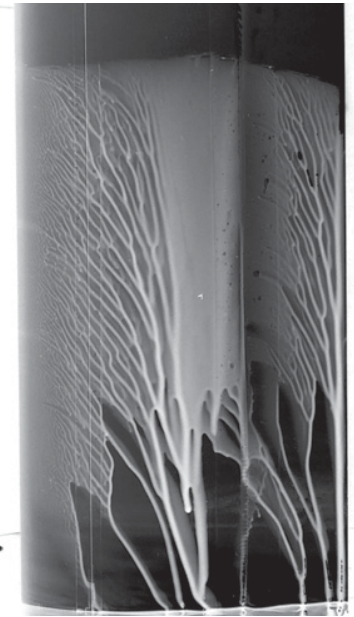

Figure 5a no VGs, $\gamma=\mathbf{0}$ deg.

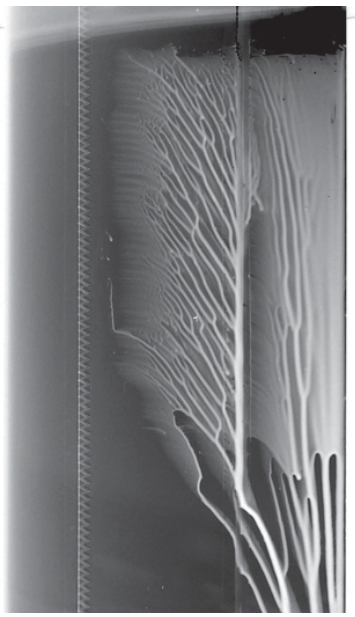

Figure 5b no VGs, zig-zag tape, $\gamma=0$ deg.

the free stream flow direction is from left to right

with different spacing are a little bit confusing and it is difficult to decide which 
configuration is better, likewise compared with conventional triangular VGs with larger spacing (the superior case of the conventional triangular VGs), see Fig. 11. Moreover the comparison with all oil visualization cases was not possible to accomplish, because the measurement was performed only for one VGs position of $\mathrm{x}_{2}$.

The last experiment was the pressure distribution measurements and the lift slopes evaluation. The best results were obtained for conventional VGs, which corresponds with oil visualization results. The highest lift coefficient increment was achieved for conventional rectangular VGs $\left(\mathrm{x}_{2}, \Delta \mathrm{z}_{2}\right)$. The results for low-profile VGs are in

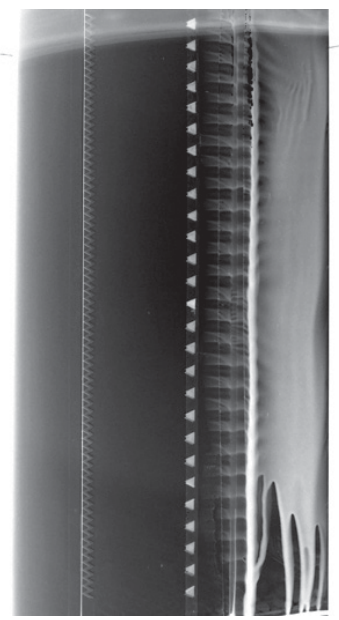

Figure 6a

rectangular VGs (h1,

$\left.x_{1}, \Delta z_{1}\right)$, zig-zag

tape, $\gamma=20$ deg.

the free stream flow direction is from left to right

an agreement with oil visualization as well. However, there are some differences, mainly for the triangular conventional VGs. The lift coefficient improvement was obtained for both positions of triangular VGs, but they seem to have a negligible or no effect in oil visualization. However, it confirms the results of infrared thermography visualization. From the lift slopes is also evident range of the VGs effectiveness, which is up to an angle of attack of $10 \mathrm{deg}$. For higher angles the separation occurs upstream of vortex generators position and they do not have effect on separated flow over deflected flap anymore, see Fig. 12. The comparison of lift slopes for cases without flap deflection shows increment of lift coefficient for angles of attack from 5 deg. to 15 deg., except the conventional rectangular VGs $\left(\mathrm{x}_{1}, \mathrm{x}_{2}, \Delta \mathrm{z}_{2}\right)$. There is a slight lift coefficient decrease, see Fig. 13. Those results correspond with tuft filaments

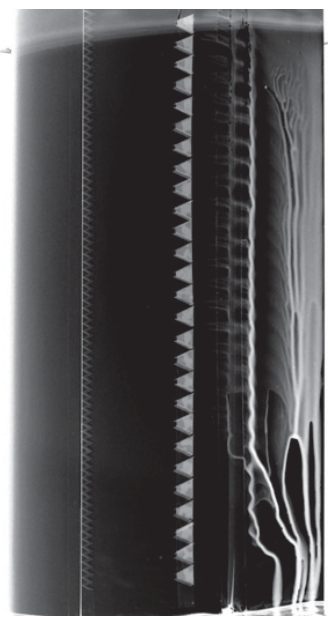

Figure 7a rectangular

VGs (h2, $\left.x_{1}, \Delta z_{2}\right)$, zig-

zag tape, $\gamma=20$ deg.

the free stream flow direction is from left to right.

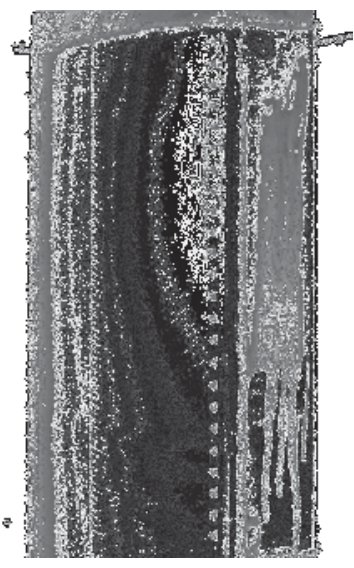

Figure 8 triangular VGs (h2, $\left.x_{2}, \Delta z_{1}\right)$, zig-zag tape, $\gamma=20$ deg.

the free stream flow direction is from left to right. 
visualization.

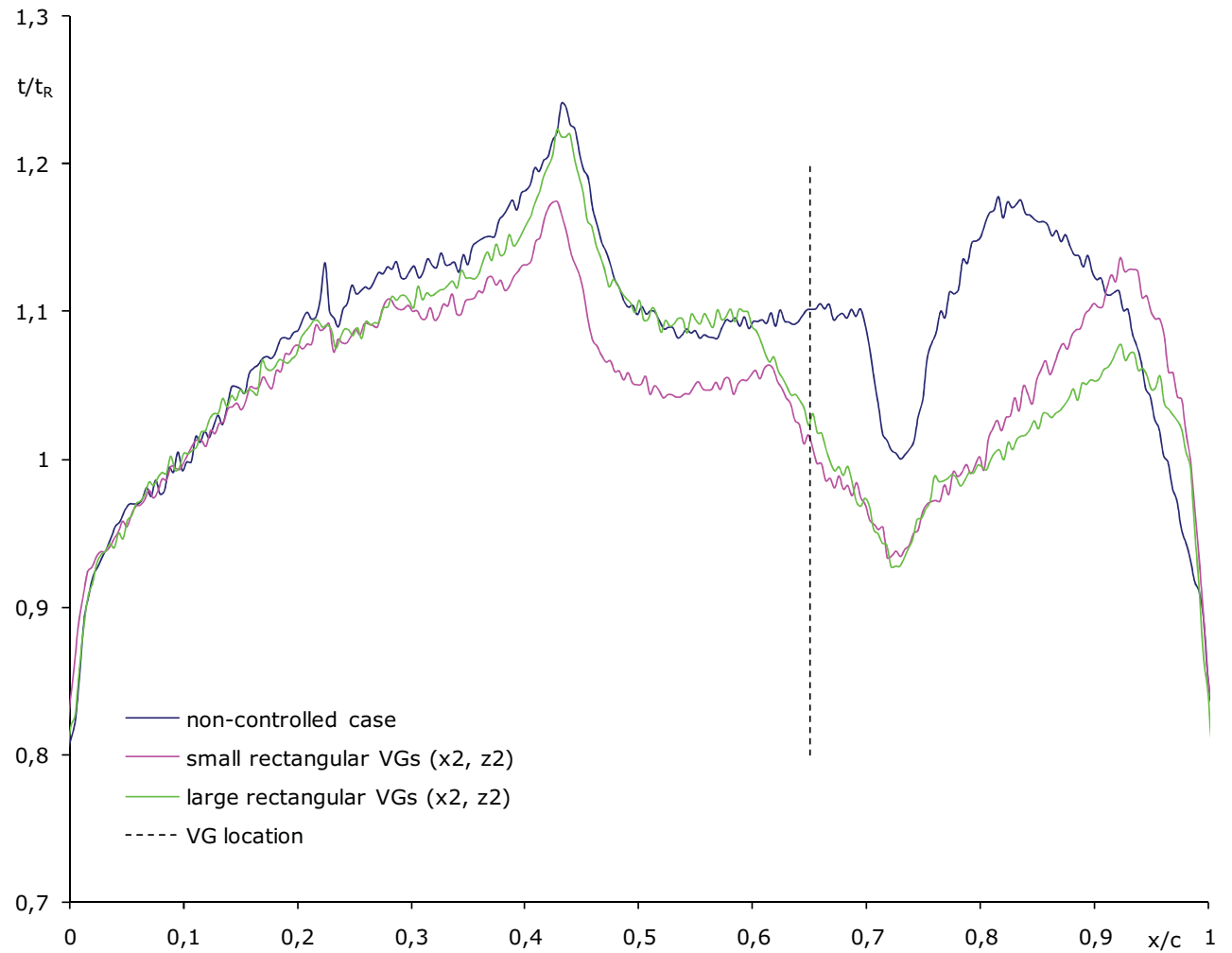

Figure 9 Comparison of non-dimensional temperature distribution over airfoil surface with zig-zag tape, $\gamma=20$ deg., $\alpha=0$ deg.

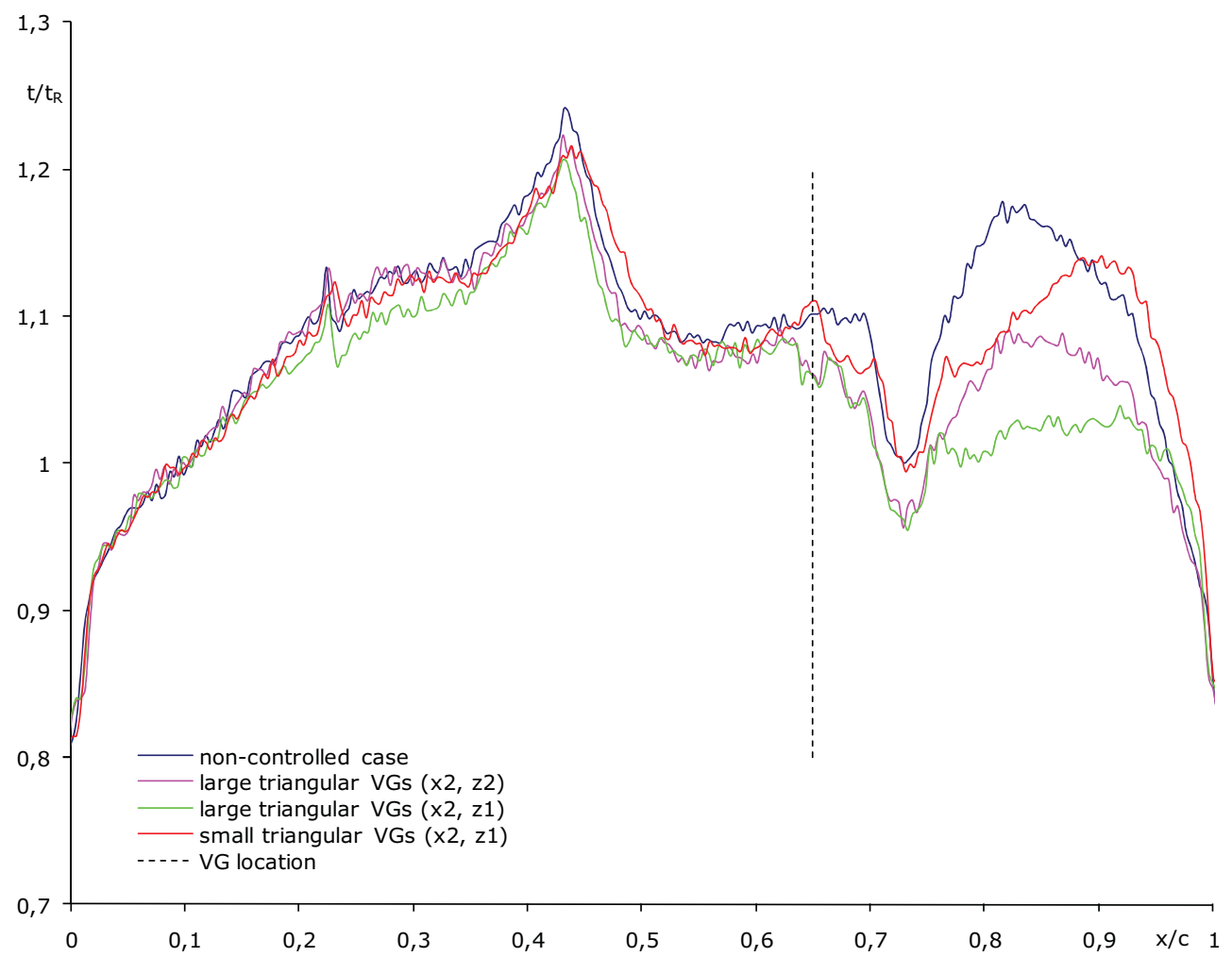

Figure 10 Comparison of non-dimensional temperature distribution over airfoil surface with zig-zag tape, $\gamma=20$ deg., $\alpha=0$ deg. 


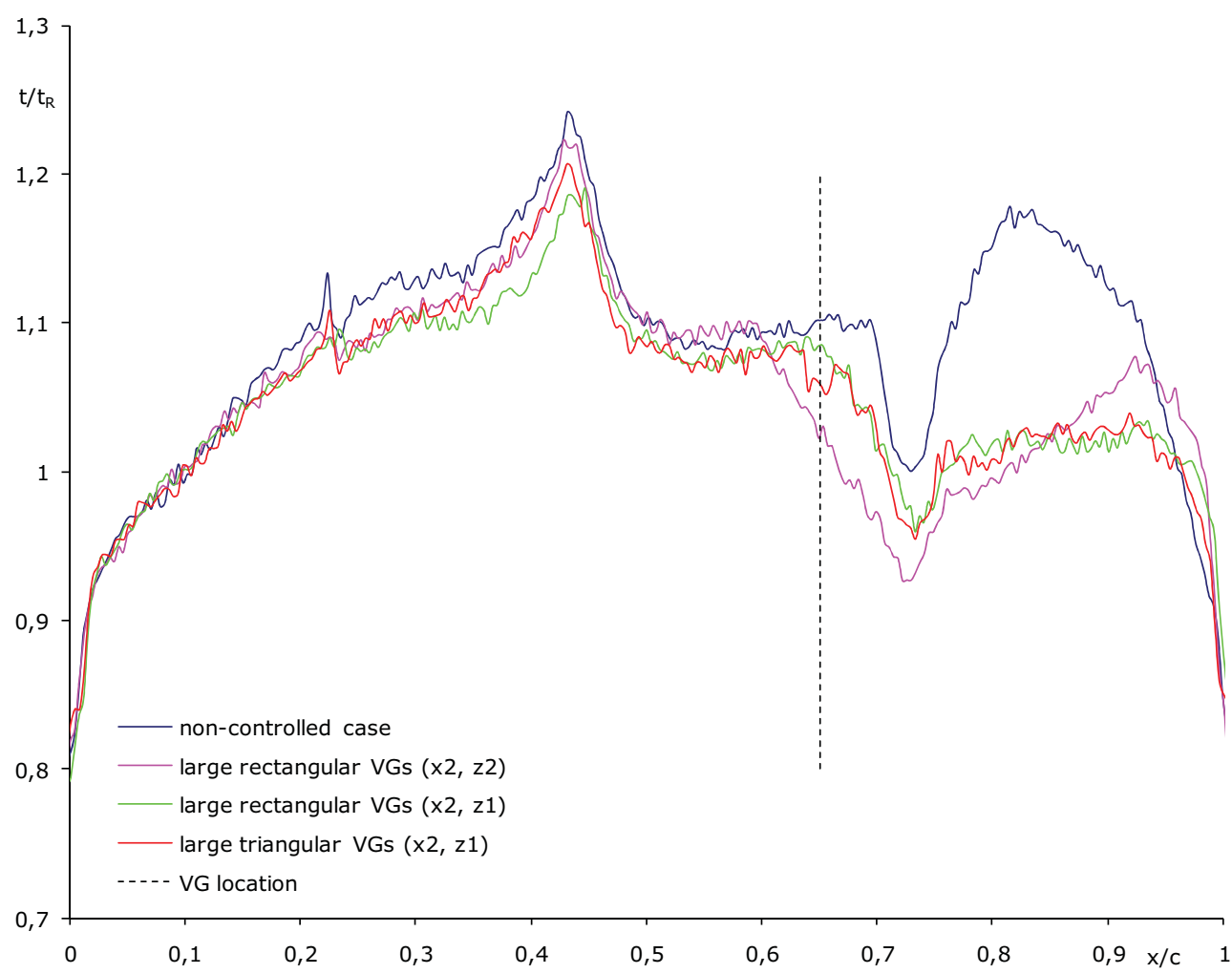

Figure 11 Comparison of non-dimensional temperature distribution over airfoil surface with zig-zag tape, $\gamma=20$ deg., $\alpha=0$ deg.

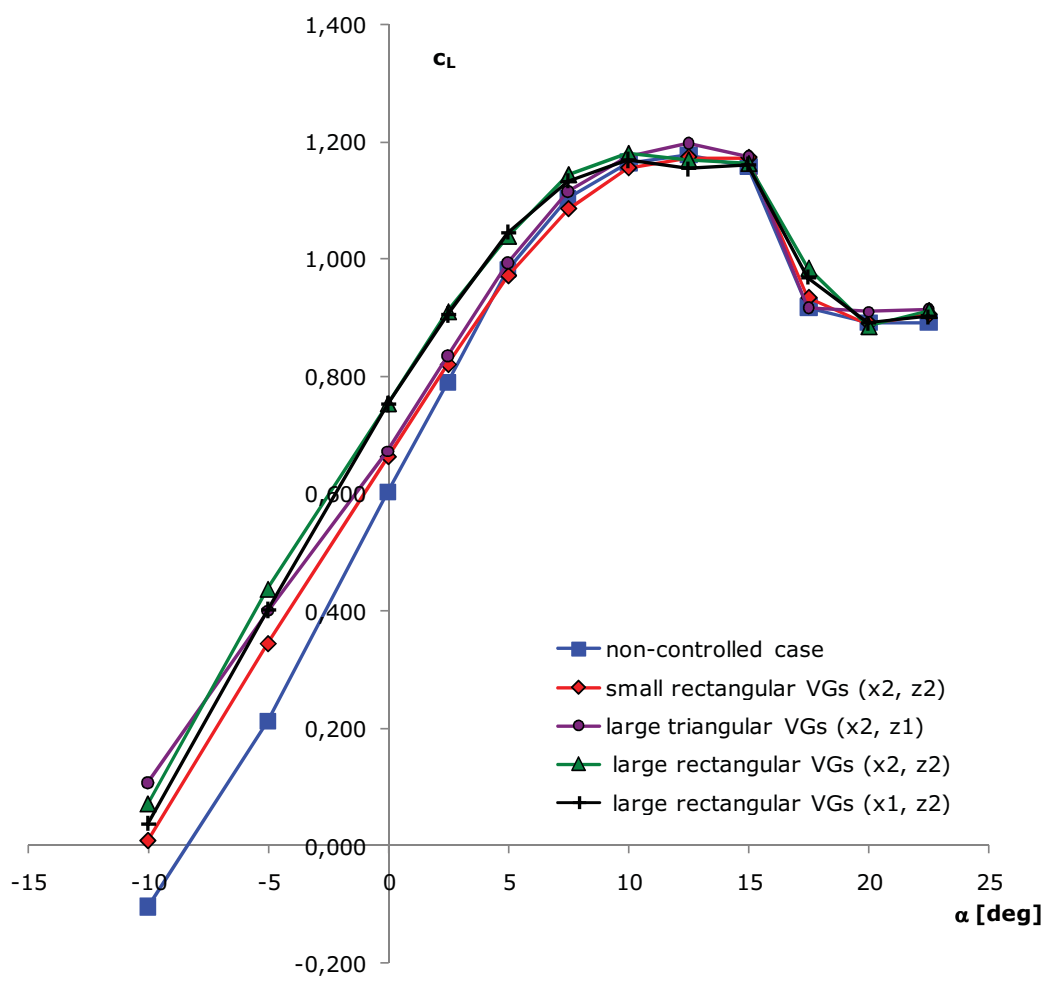

Figure 12 Lift slope comparison of non-controlled and controlled cases, $\gamma=20$ deg. 


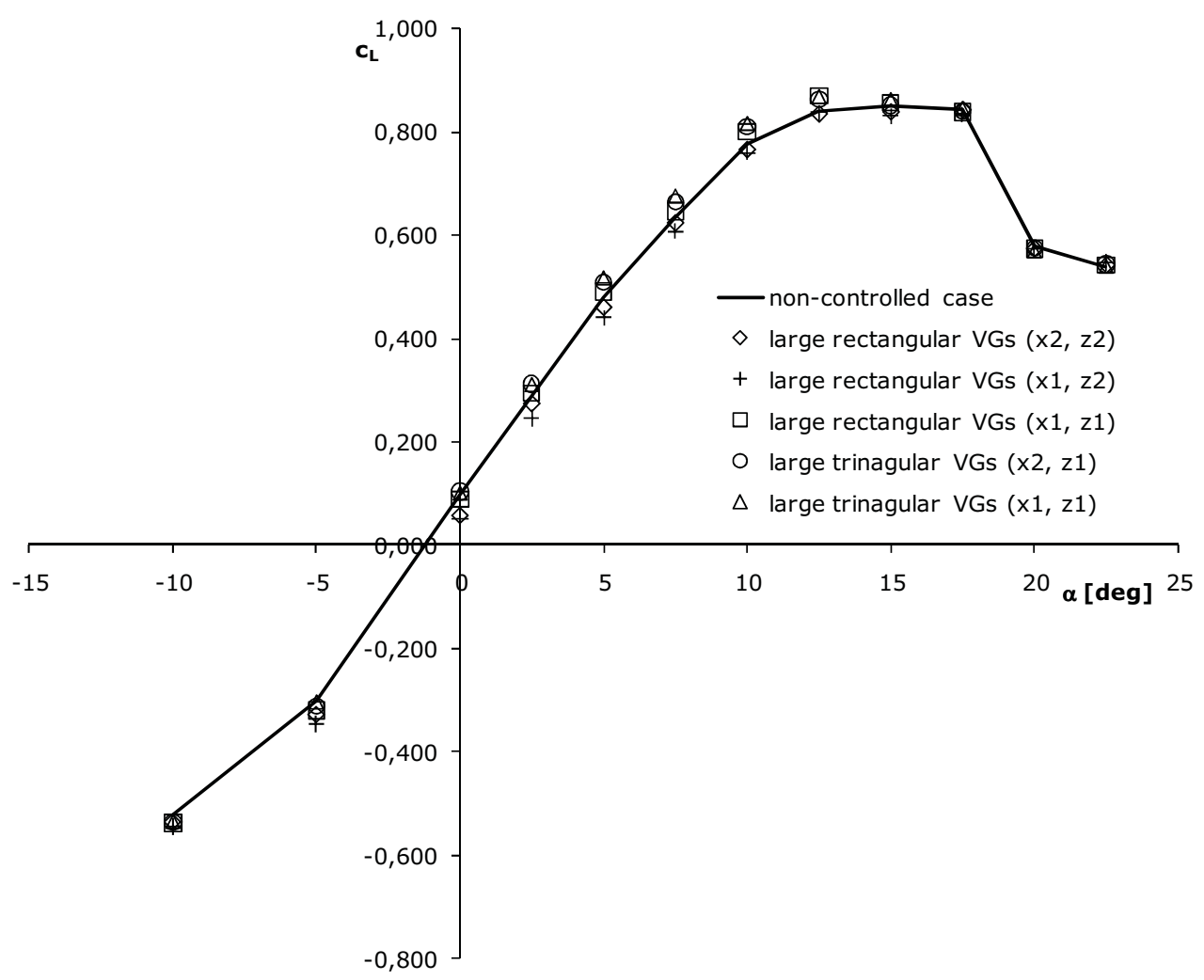

Figure 13 Lift slope comparison of controlled cases, which caused the largest lift coefficient increment at $\gamma=20 \mathrm{deg}$. (conventional VGs, $\gamma=0 \mathrm{deg}$.)

\section{Conclusion}

This investigation brings some interesting findings and consequently few questions as well.

According to the oil visualization the flow separation over deflected flap was not completely removed, however, the downstream displacement of separation onset closer to trailing edge was achieved primarily with conventional vortex generators. Moreover the rectangular vane VGs seem to be more effective than the triangular ones. This illustrates the fact that the only improvement, which was achieved with low-profile VGs, was using rectangular ones. Further, the conventional VGs are not as sensitive to position changes as the low-profile VGs, because almost the same improvement was reached for both positions using the large VGs, whereas the position played an important role in effectiveness of small ones. However, the comparable increase of lift coefficient at conventional triangular VGs application was achieved for two configurations based on lift slope measurement. These disagreements were not successfully clarified even by using further visualization method - infrared thermography. Besides, this method brings other obscurities in disapproving results and the findings interpretation.

Influence of spacing between VGs pairs appears very interesting. Whereas large rectangular VGs have more significant effect at small spacing, the triangular ones have opposite behaviour. The larger spacing between conventional rectangular VGs pairs causes relevant deterioration in lift coefficient compared to the case with small spacing. But this applies to the large VGs only. According to the oil visualization the small rectangular VGs have the same behaviour as triangular ones. 
The questions, which come with the resulting evaluation, are connected with big differences in effectiveness of rectangular and triangular VGs, with particular VGs behaviour at spacing changes as well as with results variances of different measurement methods. Thus the following work will focus on better understanding of those differences by means of vortices visualization produced by pairs of vortex generators and numerical simulation of VG control on deflected flap. The future study should focus on drag force measurement for VGs drag penalties determination and verification of numerical simulations as well.

\section{ACKNOWLEDGEMENT}

The work has been supported by the Ministry of Education, Youth and Sports of the Czech Republic, within project No.1M06031. Support by the Czech Science Foundation under grants No. P101/10/1230, No. $101 / 08 / 1112$ and GA103/09/0977 is gratefully acknowledged.

\section{NomenClature}

e vortex generator length, $\mathrm{m}$

$\mathrm{h}$ vortex generator height, $\mathrm{m}$

$t / t_{R}$ non-dimensional temperature

$L \quad$ distance between ends of vortex generators in one pair (see Fig. 2), $m$

Re Reynolds number

Tu Turbulence intensity, \%

$v_{\infty}$ free stream velocity, $\mathrm{m} / \mathrm{s}$

$\mathrm{x} / \mathrm{c}$ non-dimensional distance downstream of leading edge

$x_{1} \quad x / c=0.5632$

$\mathrm{x}_{2} \quad \mathrm{x} / \mathrm{c}=0.65$

$\Delta \mathrm{X}_{\mathrm{VG}}$ distance between flow separation location and vortex generators position, $\mathrm{m}$

$\Delta \mathrm{z}$ distance between adjacent vortex generators pairs axis, $\mathrm{m}$

$\alpha$ angle of attack, deg.

$\beta$ angle between flow direction and vortex generator, deg.

$\gamma \quad$ flap deflection, deg.

$\delta$ boundary layer thickness, $\mathrm{m}$

\section{REFERENCES}

[1] Tavoularis S.: Measurement in Fluid Mechanics, New York, Cambridge University Press, 2005, p. 354

[2] Lin J.C.: Review of research on low-profile vortex generators to control boundary-layer separation, Progress in Aerospace Science, 2002, Vol. 38, pp. 389-420

[3] Shan H., Jiang L., Liu C., Love M., Maines B.: Numerical study of passive and active flow separation control over a NACA0012 airfoil, Computer \& Fluids, 2008, Vol. 37, pp. 975-992

[4] Godard G., Stanislas M.: Control of a decelerating boundary layer. Part 1: Optimization of passive vortex generator, Aerospace Science and Technology, 2006, Vol. 10, pp. 181-191 
[5] Popelka L.: Wind Tunnel Test Section for Airfoils and Bodies, Research Programme Feasibility Studies, Conference Topical Problems of Fluid Mechanics, Institute of Thermomechanics AS CR, Prague, 2008, pp. 85-88

[6] Součková N., Šimurda D., Popelka L.: Control of Boundary Layer Separation on Flapped Airfoil with Low-Profile Vortex Generators, Experimental Fluid Mechanics, Liberec, 2009, pp. 310-315

[7] Kuklová J.: Metody zviditelnění proudění na obtékaném tělese, Fakulta dopravní ČVUT, bakalářská práce, 2010, p. 68 